\title{
O direito à interrupção da gravidez de fetos anencéfalos: vozes e lógicas discursivas presentes na ADPF 54
}

\author{
Milka Alves Correia Barbosa' \\ Vinícius Farias Moreira ${ }^{2}$ \\ Suzanne Érica Nóbrega Correia ${ }^{3}$
}

\section{Resumo}

Neste artigo, buscou-se analisar a lógica dos debates políticos em torno da Arguição de Descumprimento de Preceito Fundamental n 54 (ADPF 54), que transferiu para a mulher a decisão pela continuidade ou interrupção da gravidez de feto anencéfalo. Utilizou-se a Teoria do Discurso de Laclau e Mouffe para identificar discursos, articulações, pontos nodais dos grupos envolvidos no debate. Para tanto, foram cuidadosamente analisados os discursos transcritos por meio de notas taquigráficas disponibilizados no site do Supremo Tribunal Federal referentes às quatro audiências públicas. Verificou-se que entidades religiosas, Estado, sociedade civil e comunidade científica apresentaram elementos de persuasão em torno da causa, os quais apontaram para dois caminhos antagônicos. Cadeias de equivalência foram formadas por atores que eventualmente poderiam estar em posições antagônicas, mas que, no debate sobre a ADPF 54, aproximaram-se contingencialmente. Os debates em torno da ADPF 54 vão além de argumentos científicos e religiosos: refletem as lógicas discursivas, os posicionamentos políticos e as ideologias de grupos sociais envolvidos.

Palavras-chave: Teoria do Discurso. Laclau e Mouffe. ADPF 54. Anencefalia.

I Doutoranda em Administração pela Universidade Federal de Pernambuco (UFPE), Recife, Pernambuco, Brasil. Professora da Universidade Federal de Alagoas (UFAL), campus Arapiraca, Alagoas, Brasil. E-mail: milka correia@gmail.com.

2 Doutorando em Administração pela Universidade Federal de Pernambuco (UFPE), Recife, Pernambuco, Brasil. Docente da Universidade Federal de Campina Grande (UFCG). Unidade Acadêmica de Administração e Contabilidade, Campina Grande, Paraiba, Brasil.E-mail: vfmoreira02@gmail.com.

3 Doutoranda em Administração pela Universidade Federal de Pernambuco (UFPE), Recife, Pernambuco, Brasil. Docente da Universidade Federal de Campina Grande (UFCG). Unidade Acadêmica de Administração e Contabilidade. Campina Grande, Paraiba, Brasil.Email: suzanne.enc@gmail.com. 


\section{Situando a problematização}

A anencefalia tem sido alvo de longos debates no Brasil nos últimos anos, que se intensificaram a partir de uma açáo judicial promovida, em 2004, pela Confederaçáo Nacional dos Trabalhadores da Saúde (CNTS), que culminou em decisão do Supremo Tribunal Federal (STF) pelo direito da mulher de interromper a gravidez no caso de fetos anencéfalos, em abril de 2012.

A anencefalia consiste na não formaçáo completa do encéfalo, ou seja, para o diagnóstico de anencefalia observa-se a ausência dos hemisférios cerebrais e do cerebelo e uma formaçáo rudimentar do tronco cerebral. Além disso, não tendo a cobertura da calota craniana, também faz parte do diagnóstico a ausência parcial ou total do crânio. A incidência na populaçáo mundial é em torno de um a cada mil nascimentos, sendo o diagnóstico definitivo e letal em todos os casos.

Trata-se de um distúrbio de fechamento do tubo neural diagnosticável nas primeiras semanas de gestaçáo. Por diferentes razóes, o tubo neural do feto náo se fecha e deixa o cérebro exposto (NINDS, 2007). Com isso, o líquido amniótico vai gradativamente dissolvendo a massa encefálica, impedindo o desenvolvimento dos hemisférios cerebrais no feto em formação (DINIZ; VÉLEZ, 2008).

Não há tratamento, cura ou sobrevida de um feto com anencefalia. De fato, em mais da metade dos casos, os fetos não resistem à gestaçáo, e aqueles que o fazem, sobrevivem minutos ou horas fora do útero após o parto. As definiçóes a respeito da patologia podem até variar, mas a ciência médica é unânime em afirmar que, uma vez diagnosticada a anencefalia, é totalmente incompatível a ideia de desenvolvimento de vida extrauterina. Neste ponto, cabe ressaltar que os casos de eventuais fetos anencefálicos que teriam sobrevivido após o nascimento e por mais de ano náo devem ser tratados pelo diagnóstico de anencefalia (CARVALHO; YOUNG, 2012).

Segundo informaçóes da Sociedade Brasileira para o Progresso da Ciência (ADPF, 2008b), o Brasil é o quarto país no mundo em frequência de anencefalia. Estudos realizados em 41 países em cinco continentes indicaram que $90 \%$ dos países desenvolvidos e $20 \%$ daqueles em desenvolvimento permitiam a interrupçáo de gravidez em casos de anencefalia. Ao que se percebe, o mundo desenvolvido tem, por demanda da sociedade, uma legislaçáo 
adaptada para esses casos. Mais próximo, há o caso da Argentina, que desde 2003 permite a interrupçáo de gravidez em casos de fetos com malformaçóes irreversíveis e incuráveis; também destacamos o caso do Irá, cuja permissão ocorre desde 2004.

As possibilidades de interrupçáo da gravidez no Brasil sáo disciplinadas pelo seu Código Penal, o qual indica, em seu Art. 128, que náo sáo punidos abortos praticados por médicos em duas situaçóes: quando náo houver outro meio para salvar a vida da gestante e nos casos de gravidez resultante de estupro, com o consentimento da máe ou representante legal. Por esse entendimento, a interrupçáo da gravidez em casos de anencefalia sempre esteve proibida e passível de punição, seja para a máe, seja também para aqueles envolvidos nesse procedimento. Mesmo assim, verifica-se que o número de abortos realizados clandestinamente é enorme, basta observar os índices expressivos de complicaçóes decorrentes de procedimentos realizados em condiçôes precárias nas mulheres atendidas gratuitamente pelo Sistema Único de Saúde (SUS).

Admite-se, entretanto, que o Código Penal Brasileiro, elaborado em 1940, era incapaz de prever a evoluçáo tecnológica e a incorporaçáo de tecnologias por imagem, as quais atualmente possibilitam um diagnóstico preciso para os casos de fetos anencéfalos. As defesas pela legislaçáo permissiva para a interrupçáo da gravidez nesse caso fundamentam-se, conforme entende a Sociedade Brasileira de Medicina Fetal, nas alegaçóes de que se trata de um natimorto neurológico e na defesa da saúde da mãe, cuja gravidez mostra-se em maior grau de risco (ADPF, 2008b).

A consideraçáo de que o feto anencéfalo trata-se de um natimorto neurológico leva-nos a questionar os critérios de determinação do fim da vida: é possível considerar morto aquele que ainda tem batimentos cardíacos e continua respirando? Se, para o Direito brasileiro, a vida chega ao fim quando da morte encefálica, a Igreja indica que náo se pode decretar morto aquele que ainda tem sistemas em funcionamento.

As alegaçóes em torno da saúde da mulher baseiam-se nas estatísticas médicas, que têm demonstrado que a gravidez de feto anencefálico, comparada à gravidez de feto regularmente formado, também traz maiores riscos à saúde, entre eles a elevaçáo da pressáo, podendo levar a quadros de eclâmpsia e pré-eclâmpsia; o aumento da produçáo de líquido amniótico, que pode levar a 
descolamento da placenta; e, até mesmo, por falta da formaçáo craniana completa, o mau posicionamento do feto no útero materno (ANIS, 2004). Além disso, a Federaçáo Brasileira das Associaçóes de Ginecologia e Obstetrícia alerta para o aumento da morbidade, o aumento dos riscos durante a gestaçáo, o aumento dos riscos obstétricos no parto e no pós-parto e consequências psicológicas severas (ADPF, 2008b).

Obviamente que a questão da interrupção da gravidez em casos de anencefalia náo se restringe a discussóes jurídicas, médicas ou bioéticas. Manifestaçóes de cunho moral, filosófico e religioso culminaram em quatro audiências públicas realizadas entre agosto e setembro de 2008, quando a Corte Suprema do Estado buscou conhecer os diversos enfoques e olhares da sociedade, dos meios médicos e da comunidade científica sobre a questáo. Em 2012, o julgamento da Arguiçáo de Descumprimento de Preceito Fundamental no 54 (ADPF 54) pelo STF representou um marco histórico na Justiça brasileira, quando o Estado transferiu para a mulher a decisáo pela continuidade ou interrupção da gravidez de feto anencéfalo.

Neste trabalho, buscamos explorar a lógica dos debates políticos que ocorreram em torno da ADPF 54, procurando ouvir as vozes e conhecer os discursos dos diferentes atores que integraram as audiências públicas acerca do tema. Para tanto, alguns questionamentos foram norteadores: quem são os sujeitos envolvidos no debate sobre a ADPF 54? Como eles se articularam e constituíram cadeias de equivalência e de diferenças diante das discussóes sobre a ADPF 54? Quais posiçóes ocuparam dentro das cadeias discursivas em torno da ADPF 54?

Nesse sentido, utilizamos a Teoria do Discurso para caracterizar e analisar as formas como os diferentes sujeitos se articularam, diferenciaram-se, lutaram e assumiram posicionamentos em relaçáo à $\mathrm{ADPF}$, que trata sobre a possibilidade de interrupçáo da gravidez em casos de anencefalia.

\section{A ADPF 54}

Diniz et al. (2009) indicam que o recurso ao Poder Judiciário para a autorização da interrupção da gravidez em caso de feto incompatível com a vida é um fenômeno que teve início nos anos 90 no Brasil. Em 2004, uma açáo de anencefalia foi apresentada ao STF, por meio de uma Arguiçáo de 
Descumprimento de Preceito Fundamental (ADPF), pela CNTS, com apoio do Instituto de Bioética, Direitos Humanos e Gênero (Anis). A iniciativa daquelas organizaçóes foi motivada por um requerimento que o STF recebera meses antes que dizia respeito a uma autorização para interrupçáo da gravidez de uma jovem de 18 anos, de Teresópolis (Rio de Janeiro), com diagnóstico de feto anencefálico. O parto, com a morte do bebê apenas sete minutos depois, ocorreu antes de decisão da Justiça sobre o abortamento (MELLO, 2012).

Naquele mesmo ano, entre os meses de julho e setembro, uma liminar concedida pelo STF autorizou mulheres grávidas de fetos com anencefalia a optar pela interrupçáo da gestaçáo e protegeu os profissionais de saúde que atuassem em tal procedimento médico. Em função dessa medida, a gestante que quisesse interromper a gravidez em caso de anencefalia náo necessitava de alvará judicial. No entanto, diante de fortes pressóes de alguns setores da sociedade, a liminar foi cassada pelo Supremo em outubro do mesmo ano.

Em 2008, foram realizadas audiências públicas, quando foram ouvidas as diferentes vozes acerca da interrupção de gestação de fetos anencéfalos. Entre outubro de 2008 e o início de 2011, o processo aguardou entrada na pauta do STF. Até que, em março de 2011, o ministro Marco Aurélio apresentou seu relatório, com uma descriçáo geral do processo, e pediu pauta para julgamento, que foi marcado para 11 de abril de 2012. Vale pontuar que, ainda em abril de 2009, a Advocacia Geral da União emitiu parecer favorável à antecipaçáo terapêutica do feto em casos de anencefalia, baseando-se na Constituição Federal.

Ao apreciar a Arguiçáo de Descumprimento de Preceito Fundamental no 54 (ADPF 54), o Supremo decidiu, por oito votos a dois, pela náo criminalizaçáo da interrupçáo da gravidez de fetos com diagnóstico de anencefalia. A sessão durou dois dias e foi considerada por alguns ministros como um dos julgamento mais importante de toda a história da corte. Mais do que não considerar crime, a decisão pressupóe que a interrupção da gestação não pode sequer ser considerada aborto, considerando-se a impossibilidade de vida extrauterina.

É preciso lembrar que, antes do julgamento da ADPF 54, o aborto em caso de anencefalia no feto era ilícito e as mulheres que desejavam interromper a gestaçáo buscavam individualmente autorização judicial. Porém, não 
havendo garantias de obter a autorização, as mulheres ficavam na expectativa da interpretaçáo que o juiz ou promotor dava a cada caso (DINIZ et al., 2009). Considerando a realidade do judiciário brasileiro, náo raras eram as situaçôes em que o parto chegava a acontecer antes da decisáo judicial.

Ao mesmo tempo, a decisáo do Supremo corrobora a Lei no 9.434/97, mais conhecida como Lei do Transplante, segundo a qual a vida cessa com a morte encefálica ou morte cerebral. Assim, do ponto de vista jurídico, se não há vida no feto anencéfalo, não há por que prolongar a gravidez e incorrer em riscos de saúde e prejuízos psicológicos à gestante. Portanto, à luz da ADPF 54, a mulher poderá interromper a gravidez, diante do diagnóstico inconteste, sem a intervenção do Estado.

Contra-argumentando, a reaçáo da Igreja ao aborto de anencéfalos é bastante severa, náo somente pela puniçáo, mas principalmente pela negativa em aceitar as exceçóes legalmente permitidas, como, por exemplo, nos casos em que o procedimento abortivo se faz necessário para salvar a vida da máe (KIRIMI; PINNA, 2011).

Ao mesmo tempo, o posicionamento do Supremo também protege judicialmente os profissionais da saúde, uma vez que todos os envolvidos em um procedimento de aborto (à exceçáo daqueles permitidos em lei) poderiam estar cometendo os crimes tipificados nos artigos 125 e 126 do Código Penal, que estipulam penalidade para abortos provocados por terceiros (FRANCO, 2012). Ademais, a descriminalização de aborto de feto anencéfalo apresentou um novo conceito médico, a antecipaçáo terapêutica de parto, posteriormente reconhecido pelo Conselho Federal de Medicina (CFM, 2004), ao definir o feto com anencefalia como natimorto cerebral.

Com base na decisão do STF, o CFM definiu regras para o aborto de fetos anencéfalos, as quais têm força de lei para médicos, regulamentando que estes podem fazer a interrupçáo de gravidez desde que observem algumas condiçóes. A primeira delas é o interesse e a concordância da gestante. Além disso, também é necessário que haja atestado de anencefalia do feto assinado por dois médicos e exame de ultrassonografia, a partir da $12^{\mathrm{a}}$ semana de gravidez, comprovando o diagnóstico.

Até aqui, aparentemente a discussáo sobre a ADPF 54 limita-se a posiçóes conflitantes entre religiosos e cientistas. No entanto, há outros atores envolvidos nesse debate e passaremos a conhecê-los na próxima seção. 


\section{As vozes que ecoam em torno da ADPF 54}

Há tempos a discussáo sobre a legalizaçáo e o caráter moral do aborto voluntário ou induzido provoca reaçóes diferentes, mobiliza grupos a expor e defender seus pontos de vista, o que por vezes resulta em posicionamentos adversos e nem sempre fundamentados por argumentos claros que sustentem a adesáo a uma posiçáo favorável ou contrária à sua legalizaçáo (DOMINGUES, 2008).

Além de evocar questionamentos no âmbito da saúde, importa ressaltar que se configuram no debate sobre a legalização do aborto: (a) as conquistas do movimento feminista, consubstanciadas em documentos nacionais e internacionais, no sentido de a mulher ser considerada capaz de tomar decisóes éticas sobre sua sexualidade e reproduçáo; e (b) os avanços da medicina e da genética relacionados ao processo de fecundaçáo, ao desenvolvimento do feto e embriáo e à segurança dos métodos para interromper uma gravidez (REDE FEMINISTA DE SAÚDE, 2005).

O caráter legal ou ilegal do aborto induzido constitui um tema complexo no âmbito dos conflitos morais, na medida em que imbrica e confronta-se com diferentes posiçóes políticas, morais e religiosas no tratamento do tema. Por isso, "a busca de consenso ou, mesmo, de diálogo entre os extremos morais envolvidos no debate sobre a moralidade do aborto acarreta uma disputa acirrada, em meio a embates, enfrentamentos e articulaçóes políticas" (RIBEIRO; SPINK, 2012, p. 36).

Para uns, o aborto é uma questáo de foro íntimo; para outros, é uma questáo moral fundamental sobre a origem da vida humana e, portanto, é imperativa a vigilância rigorosa sobre essa prática. $\mathrm{O}$ abortamento induzido é um tema capaz de influenciar expectativas de eleiçóes políticas, criar constrangimentos entre naçóes, provocar rompimentos entre entidades e instituiçóes (DINIZ; DAMASCENO, 2001).

De modo geral, percebemos ainda que o aborto impóe a escolha de posicionamento de quem é a favor ou contra, determinando-se, assim, o lugar a ser ocupado no espaço público de debate. Junto à polarizaçáo dessa discussão, entra-se em uma disputa em torno do direito à vida, como se somente uma das partes envolvidas pudesse protegê-la. Como consequência, outros pontos de vista sobre a compreensáo do tema sáo excluídos, minimizados, reduzidos. 
Isso acontece por se tratar de um tema que mexe com tabus e preconceitos, envolvendo a religiāo e os preceitos morais e éticos de nossa sociedade.

É nesse cenário que a discussão sobre o aborto ou interrupçáo da gravidez de fetos anencéfalos insere-se. No entanto, para Ribeiro e Spink (2012), o caso do aborto de feto anencéfalo náo pode ser compreendido dentro dos limites da argumentação polarizada com a qual vem sendo tratado o tema do aborto, qual seja, de um lado, a ideia feminista de que o corpo pertence às mulheres e, de outro, o direito potencial à vida do feto, segundo princípios morais e religiosos.

Corroborando, para Kirimi e Pinna (2011), a polêmica inclui a colisáo dos Direitos e Garantias Fundamentais em virtude da ilegalidade do aborto e da "legalidade" do aborto nos casos de anencefalia; o direito à vida intrauterina do feto diagnosticado com anencefalia; e o direito da máe à saúde física e mental e à sua liberdade de autonomia reprodutiva, quando opta pela realizaçáo do aborto.

Para um entendimento das múltiplas vozes que ecoam acerca da discussão que envolve a interrupção da gravidez em caso de anencefalia, optamos pela análise das notas taquigráficas das audiências públicas do STF, em que várias instituições se posicionaram, as quais dividimos em três grandes segmentos: o religioso, o médico-científico e o social, identificando seu posicionamento a favor ou contra, conforme o quadro 1, a seguir apresentado. 
Quadro I - Segmentos e posicionamento em relação à anencefalia

\begin{tabular}{|c|c|c|}
\hline Segmento & Instituições & Posicionamento \\
\hline \multirow{4}{*}{ Religioso } & $\begin{array}{l}\text { Conferência Nacional dos Bispos do Brasil } \\
\text { (CNBB) }\end{array}$ & Contra \\
\hline & Igreja Universal & A favor \\
\hline & ONG Católicas pelo Direito de Decidir & A favor \\
\hline & Associação Médico-Espírita do Brasil (AME) & Contra \\
\hline \multirow{9}{*}{ Médico-científico } & Conselho Federal de Medicina & A favor \\
\hline & $\begin{array}{c}\text { Federação Brasileira das Associações de } \\
\text { Ginecologia e Obstetrícia }\end{array}$ & A favor \\
\hline & Sociedade Brasileira de Medicina Fetal & A favor \\
\hline & Sociedade Brasileira de Genética Médica & A favor \\
\hline & $\begin{array}{l}\text { Sociedade Brasileira para o Progresso da } \\
\text { Ciência }\end{array}$ & A favor \\
\hline & Associação Brasileira de Psiquiatria & A favor \\
\hline & $\begin{array}{c}\text { Instituto de Bioética, Direitos Humanos e } \\
\text { Gênero }\end{array}$ & A favor \\
\hline & $\begin{array}{l}\text { Comissão de Ética e Cidadania da } \\
\text { Academia Fluminense de Medicina }\end{array}$ & Contra \\
\hline & $\begin{array}{c}\text { Elizabeth Kipman Cerqueira, ginecologista } \\
\text { e obstetra }\end{array}$ & Contra \\
\hline \multirow{11}{*}{ Social } & Associação Nacional Pró-Vida e Pró-Família & Contra \\
\hline & $\begin{array}{l}\text { Frente Parlamentar em Defesa da Vida - } \\
\text { Contra o Aborto }\end{array}$ & Contra \\
\hline & $\begin{array}{l}\text { Organização Mundial da Saúde para } \\
\text { Assuntos de Saúde da Mulher }\end{array}$ & A favor \\
\hline & $\begin{array}{l}\text { Movimento Nacional da Cidadania em } \\
\text { Defesa da Vida - "Brasil sem aborto" }\end{array}$ & Contra \\
\hline & Ministério da Saúde & A favor \\
\hline & Escola de Gente & A favor \\
\hline & Associação de Desenvolvimento de Família & Contra \\
\hline & $\begin{array}{l}\text { Rede Nacional Feminista de Saúde, Direitos } \\
\text { Sexuais e Direitos de Reprodução }\end{array}$ & A favor \\
\hline & Conselho Nacional dos Direitos da Mulher & A favor \\
\hline & $\begin{array}{c}\text { Conectas Direitos Humanos e Centro de } \\
\text { Direitos Humanos }\end{array}$ & A favor \\
\hline & $\begin{array}{c}\text { Secretaria Especial de Políticas para as } \\
\text { Mulheres }\end{array}$ & A favor \\
\hline
\end{tabular}

Fonte: ADPF (2008a, b, c, d). 
No segmento religioso, prevaleceu a defesa pela vida, com destaque aos argumentos apresentados pela Igreja Católica e pelos Espíritas. Representando a Conferência Nacional dos Bispos do Brasil, o padre Luiz Bento seguiu em defesa da humanidade do indivíduo que ainda está em gestaçáo, mesmo que este esteja com má formaçáo. A Igreja defendeu a dignidade humana, que precisa ser tutelada e respeitada: "o feto anencéfalo é um ser humano vivente e sua reduzida expectativa de vida náo nega seus direitos, a sua identidade" (ADPF, 2008a, p. 6). Mesmo reconhecendo o sofrimento da mãe e da família, a Igreja indicou que o ato não se justifica nem autoriza o sacrifício da vida. Ela defendeu que a decisáo pelo controle da vida náo está nas máos dos humanos, é divina. Além disso, argumentou que o direito ao aborto do anencéfalo representaria uma eutanásia pré-natal por consciência dos pais, e isso se configuraria como a admissão de ato discriminatório, racista e celetista.

Pela Associação Médico-Espírita do Brasil, Marlene Nobre, que é médica ginecologista, apresentou argumentos científicos em defesa da vida do anencéfalo, indicando também que não é possível falar de direito da mulher quando há um direito que se sobrepóe, que é o direito à vida. Marlene Nobre sinalizou que somos evolucionistas, que o acaso não explica a vida, pois a vida é um bem fundamental, é um bem outorgado, e deve ser respeitada e vivida. Para ela, "a vida do anencéfalo sobrepuja todos os outros direitos, é um bem fundamental que lhe pertence" (ADPF, 2008a, p. 54).

Por outro lado, e ainda representando o segmento religioso, a posiçáo da Igreja Universal do Reino de Deus, representada pelo bispo Carlos Macedo de Oliveira, defendeu a laicidade do Estado e indicou que nos casos de anencefalia deve prevalecer o desejo da mulher que passa ou venha a passar por esse drama (ADPF, 2008a). Nessa mesma linha de pensamento, a Dra. Maria José Fonteles Rosado Nunes, professora e pesquisadora do Conselho Nacional de Desenvolvimento Científico e Tecnológico (CNPq) que estuda o cruzamento das questóes de gênero e religiáo, argumentou em representaçáo à ONG Católicas pelo Direito de Decidir. Segundo Nunes, "as leis que regulam a sociedade brasileira devem, portanto, refletir essa laicidade [...]. O Estado náo pode regular-se por definiçóes religiosas" (ADPF, 2008a, p. 40).

No segmento médico-científico, a posição preponderante foi a favor do direito à interrupçáo da gravidez nos casos de anencefalia. Para esses casos, não se faz uso do termo "aborto", fala-se em antecipação terapêutica do 
parto, conforme esclarece Roberto D'Ávilla, pelo Conselho Federal de Medicina (ADPF, 2008b). Para ele, a exclusão do direito da mulher representa a judicializaçáo da medicina, alegando que a gravidez de um feto anencéfalo é um risco à saúde da mulher e que é papel do médico esclarecer a situaçáo aos pacientes.

A Federaçáo Brasileira das Associaçôes de Ginecologia e Obstetrícia, representada pelo Dr. José Andalaft Neto, argumentou sobre a saúde da mulher baseando-se em estudos da Organizaçáo Mundial de Saúde e destacando as principais repercussóes para a vida da mulher que prossegue com a gestaçáo de feto anencéfalo: aumento da morbidade, aumento dos riscos durante a gestação, aumento dos riscos obstétricos no parto e no pós-parto e consequências psicológicas severas (ADPF, 2008b).

Uma das razōes da gravidade das consequências psíquicas decorre do fato de que as tecnologias atuais permitem o diagnóstico da anencefalia a partir do terceiro mês de gestação e, sendo positivo, a máe estaria submetida a permanecer em um luto prolongado ao tempo em que vê sua barriga crescer. $\mathrm{O}$ impacto do diagnóstico e a experiência de tortura vivenciada pelas mulheres foram objetivos da arguiçáo da doutora em antropologia e pós-doutora em bioética Débora Diniz, representante da Anis (ADPF, 2008b). Colaborando, o médico psiquiatra, livre-docente pela Universidade Federal do Rio de Janeiro e representante da Associaçáo Brasileira de Psiquiatria Dr. Talvane Moraes destacou que a saúde deve ser entendida como bem-estar biopsicossocial e, em nome da saúde mental da mulher, defendeu a autodeterminaçáo da gestante para decidir livremente sobre a antecipaçáo terapêutica do parto nos casos de anencefalia (ADPF, 2008c).

Heverton Pettersen, da Sociedade Brasileira de Medicina Fetal, destacou que o anencéfalo é um natimorto neurológico, indicando que ele náo tem sequer o desenvolvimento do sistema nervoso central (ADPF, 2008b). Para a medicina, o critério do fim da vida é a morte cerebral, de modo que, no caso do anencéfalo, ele já nasceria morto. Essa posição também foi defendida pelo professor livre-docente em genética médica pela Universidade de Sáo Paulo Dr. Thomaz Gollop, que, falando em nome da Sociedade Brasileira para o Progresso da Ciência, afirmou que o anencéfalo é um morto cerebral que tem batimentos cardíacos e respiraçáo (ADPF, 2008b). 
Sobre o papel do médico, o Prof. Dr. Salmo Raskin, presidente da Sociedade Brasileira de Genética Médica, defendeu que o médico tem o dever de esclarecer o casal sobre a situaçáo da anencefalia, o que deve acontecer de forma náo diretiva e não coercitiva. Para Raskin, o médico náo deve indicar sua visão pessoal, pois o casal deverá achar a resposta em sua própria história de vida, nos seus conceitos religiosos e filosófico-morais, na condiçáo sócio-econômico-cultural e, ainda, na história do próprio casal (ADPF, 2008b).

Embora a visão médico-científica tenha sido predominantemente favorável ao direito da mulher em casos de anencefalia, houve posiçóes contrárias, como a esboçada pela Comissáo de Ética e Cidadania da Academia Fluminense de Medicina, representada pelo Sr. Dernival Brandão, especialista em ginecologia e obstetrícia com mais de cinquenta anos de profissáo. Para Brandáo, "a reduzida expectativa de vida náo limita os direitos do nascituro" (ADPF, 2008c, p. 86), acrescentando ainda que a vida humana deve ser preservada e defendida por todos, principalmente pelo poder público. Nessa linha, a Sra. Elizabeth Cerqueira, também médica especialista em ginecologia e obstetrícia, negou a possibilidade de diagnóstico de anencefalia quando o bebê está no ventre materno, indicando que a possibilidade da interrupçáo terapêutica pode ser danosa à máe e fazendo links da anencefalia com o eugenismo e o aborto (ADPF, 2008d).

O terceiro âmbito foi o social, composto por segmentos políticos e associaçóes da sociedade. Na esfera política, destacou-se o discurso do Ministro da Saúde à época, José Gomes Temporão, que ressaltou as condiçōes de diagnóstico da anencefalia pelo sistema público de saúde brasileiro. $\mathrm{O}$ ministro assegurou que o SUS já oferece o diagnóstico seguro às mulheres durante o pré-natal e que é acessível, com possível cobertura universal pelo sistema público de saúde. Segundo ele, "a imagem ecográfica é clara em diagnosticar um feto com anencefalia. Na medicina fetal há duas certezas no diagnóstico por imagem: o óbito e a anencefalia" (ADPF, 2008c, p. 5). O ministro apontou ainda que, em casos de diagnóstico positivo de anencefalia, a gestante é encaminhada para um novo exame, feito por uma equipe médica diferente, que certificará o diagnóstico.

Procurando distinguir a anencefalia de casos de deficiência, estiveram presentes nas audiências públicas como representantes da sociedade: a) a Escola da Gente, que atua na inclusáo de pessoas com deficiência na sociedade, 
representada pela jornalista Cláudia Werneck, que é favorável à antecipaçáo terapêutica do parto em casos de anencefalia porque esta náo se trata de uma deficiência. Werneck destacou a posiçáo da Escola de repúdio à eugenia, que seria representada pela interrupção de uma gravidez em casos de deficiência, mas que esse não era o caso (ADPF, 2008c); b) a Rede Nacional Feminista de Saúde, Direitos Sexuais e Direitos Reprodutivos, defendida pela Profa. Dra. Lia Zanotta Machado, que trouxe para as audiências vozes, rostos e sentimentos das mulheres que se defrontaram com o diagnóstico de feto anencéfalo. Essas máes apresentaram suas experiências e seus traumas. Para Machado, deficiência é uma situação em que é possível estar no mundo; a anencefalia, náo. A professora defendeu o direito à vivência do luto quando do diagnóstico da morte cerebral (ADPF, 2008c).

Em defesa do direito da mulher, desde que bem orientada, destacaram-se também as seguintes vozes: 1) da Secretaria Especial de Políticas para as Mulheres, vinculada à Presidência da República, por Nilcéa Freire, que defendeu que a mulher precisa ser vista como sujeito de direito e, portanto, respeitada como tal. Ela indicou ainda que as mulheres náo necessitam de tutela de instituiçóes religiosas ou científicas, elas precisam de informaçóes claras e apoio para suas decisóes (ADPF, 2008d); 2) do Conselho Nacional dos Direitos da Mulher, ligado à Secretaria Especial; 3) da Organizaçáo Mundial da Saúde para Assuntos da Saúde da Mulher, nas palavras do deputado federal José Aristodemo Pinotti, que indicou que o termo "aborto" representa a interrupçáo de uma potencialidade de vida e que, no caso da anencefalia, recomenda-se o termo "interrupçáo da gestaçáo", "interrupçáo de uma gestaçáo com feto que não tem potencialidade de vida" (ADPF, 2008b, p. 75); "quem não tem cérebro, não tem vida" (ADPF, 2008b, p. 77); e 4) do Conectas Direitos Humanos e Centro de Direitos Humanos, representado pela professora de saúde coletiva da Universidade Federal de Sáo Paulo Elionora Menecucci de Oliveira, que destacou a necessidade de atentar à saúde física e psíquica da gestante em caso de anencefalia incompatível com a vida extrauterina (ADPF, 2008d).

A Associaçáo Nacional Pró-Vida e Pró-Família, representada pelo doutor em medicina pela Universidade Federal do Rio de Janeiro Rodolfo Acatauassú Nunes, contestou o fato de que uma criança que está respirando tenha morte encefálica, bem como indicou a necessidade explicaçóes a respeito da interaçáo de uma criança anencefálica com sua mãe. Para Nunes, é preciso agir com 
muita prudência, pois em alguns casos pode haver certo grau de consciência primitiva. A prudência deve ser especialmente destacada quando do interesse pela doaçáo de órgáos por anencefálicos. A resoluçáo do CFM no 1.752/2004 autorizava a retirada de órgãos de crianças anencefálicas, classificando como inaplicáveis e desnecessários os critérios de morte encefálica. Evoluindo, as discussóes acerca do tema fizeram com que o Ministério da Saúde editasse nova portaria, indicando que a retirada de órgáos deveria ser precedida de diagnóstico de parada cardíaca irreversível.

Contra o direito de decisão pela anencefalia, também estiveram presentes: 1) a Associaçáo de Desenvolvimento de Família (Adef), representada pela médica endocrinologista Iêda Therezinha Verreschi, cuja missão foi a de apresentar, sob o ponto de vista técnico, a existência de diferentes casos de anencefalia, indicando que a pequena parcela dos que chegam a nascer representa vidas humanas sob ameaça (ADPF, 2008c); 2) a Frente Parlamentar em Defesa da Vida - Contra o Aborto, que teve como locutor o deputado federal Luiz Bassuma, o qual alertou para a falibilidade humana, indicando que "a vida náo pode ser medida em estatísticas [...]. Porque as estatísticas podem ser utilizadas de mil maneiras, vai depender de quem as defende, de quem as apresenta" (ADPF, 2008b, p. 41). Bassuma associou a anencefalia com a eutanásia, alertando que náo se pode anular aqueles que por certas circunstâncias nos incomodam. O deputado afirmou ainda que é contra o aborto, inclusive em casos de estupro, sugerindo o caminho da adoçáo como alternativa; 3) o Movimento Nacional da Cidadania em Defesa da Vida - Brasil sem Aborto, pelas palavras da professora Lenise Aparecida Garcia, que trouxe à tona a falibilidade levantada por Bassuma, ao questionar o diagnóstico inicial do caso Marcela como sendo de anencefalia, para somente depois outros médicos indicarem que se tratava de um caso de má formaçáo cerebral, descartando a anencefalia (ADPF, 2008b).

De fato, esse tema suscita grande interesse, por envolver uma miríade de questôes médicas, sociais, bioéticas, jurídicas, religiosas, morais e éticas, e tem sido alvo de acalorados debates em diversos setores da sociedade brasileira. No cerne desse contexto, conforme entendem Diniz e Vélez (2008), vislumbram-se a confusão sobre a laicidade do Estado como um bem comum, a intensa sacralizaçáo da ordem pública, a quase nenhuma adesáo à razão pública em matéria de aborto e os juízes da Suprema Corte representando guardiōes da razão pública. 


\section{Caminhos metodológicos}

Para a realizaçáo desta pesquisa, algumas etapas foram desenvolvidas. Uma vez que o objetivo do trabalho foi ouvir as vozes e conhecer os discursos dos diferentes atores que integraram as audiências públicas da ADPF 54, verificamos a necessidade de construir um corpus de pesquisa considerando os critérios de relevância, homogeneidade e sincronicidade definidos por Bauer e Aarts (2002). Dessa forma, foram coletados aspectos e dados relevantes sobre o tema específico em discussáo - o direito à interrupçáo da gravidez no caso de fetos anencéfalos. Para manter a homogeneidade dos dados, tratamos separadamente os textos, vídeos e relatos referentes à ADPF 54. Consideramos também como marco cronológico na discussão da interrupçáo da gravidez nos casos de anencefalia a liminar concedida e cassada pelo STF em 2004, de modo que os materiais coletados tentaram privilegiar um intervalo de tempo entre os anos de 2004 e 2012.

Assim, foram cuidadosamente analisados os discursos transcritos por meio de notas taquigráficas disponibilizados no site do STF referentes às quatro audiências públicas que ocorreram nos dias 26 e 28 de agosto e 4 e 16 de setembro de 2008 e que resultaram em um corpus de 350 páginas (ADPF, 2008a, b, c, d). Todo o material foi lido e tratado de forma a verificar sua pertinência e reconhecer e identificar os principais grupos envolvidos.

Para analisar tal material empírico, aproximamos a Análise do Discurso (AD) da Teoria do Discurso (TD). A AD trata da prática de analisar material empírico e informaçóes considerando-os como formas discursivas. Isso significa que tal análise trata os dados linguísticos e não linguísticos como textos, escritos, manifestos, eventos históricos, entrevistas, políticas, ideias, entre outros. Ou seja, dados empíricos são vistos como um conjunto de práticas significativas que constituem o discurso e sua realidade (HOWARTH, 2000).

Aproximando-se dessa perspectiva, em vez de aplicar uma teoria pré-existente a um conjunto de objetos empíricos, a TD procura articular seus conceitos em cada enunciado de pesquisa concreta. Os conceitos e as lógicas do framework teórico têm que ser suficientemente abertos e flexíveis para ser adaptados, deformados e transformados no processo de aplicaçáo. Para tanto, essa concepçáo exclui teorias reducionistas e essencialistas da sociedade, uma vez que significados, interpretaçóes e práticas sáo intrinsecamente ligados. 


\section{A Teoria do Discurso para ouvir as vozes envolvidas na discussão da ADPF 54}

A TD de Laclau e Mouffe foi desenvolvida no campo da retórica, da teoria da democracia, da teoria dos movimentos sociais, da teoria lacaniana da ideologia e no próprio campo filosófico. Tendo como ponto de partida uma crítica ao marxismo, Laclau (2005) aponta para um complexo social formado por uma infinitude de identidades, as quais são constituídas por meio de relaçóes discursivas antagônicas. Essa complexidade do social não é percebida pelo marxismo, o que retira dessa teoria a capacidade de análise mais refinada dos múltiplos antagonismos sociais possíveis (LACLAU; MOUFFE, 1985).

Entre os elementos centrais de investigação da TD, estáo a formaçáo de identidades, a produçáo de ideologias, as lógicas de movimentos sociais e a pluralidade de imaginários sociais. De fato, a insatisfação com os modelos teóricos de explicaçáo social levou à busca por uma abordagem alternativa para a estruturaçáo dos espaços sociais e políticos articulando uma nova concepçáo de discurso.

A TD assume que todos os objetos e açóes são significativos e que seus significados sáo conferidos por sistemas de regras contextualizados historicamente, questionando a forma como a prática social se constrói e o discurso constitui a realidade social; existe uma relaçáo entre as palavras e as coisas, para que as primeiras tenham um significado é necessário um discurso (HOWARTH; NOVAL; STRAVAKAKIS, 2000).

O discurso é entendido como um sistema de práticas significativas que formam a identidade dos sujeitos e objetos. Discursos são intrinsecamente políticos e envolvem a construção de antagonismos, demarcam fronteiras entre os incluídos e excluídos; são construçóes históricas e contingentes, visto que são vulneráveis às forças políticas e aos efeitos deslocatórios de eventos (HOWARTH; STRAVAKAKIS, 2000; BURITY, 2008). O material analisado acerca da ADPF 54 levou-nos a identificar pelo menos dois discursos que formam a identidade desses grupos: um que defende o direito à vida do feto anencéfalo e outro que defende o direito da mãe a interromper a gestaçáo em caso de anencefalia de seu bebê.

Laclau entende o discurso como uma categoria de articulação que une palavras e açóes, que tem natureza material. Discurso é prática em virtude de as açóes empreendidas por sujeitos e grupos sociais serem açóes significativas. 
No caso deste estudo, conforme já citado anteriormente, foram analisadas as vozes das várias instituiçóes ouvidas nas audiências públicas, as quais foram classificadas intuitivamente como pertencentes aos segmentos: religioso, médico-científico e social, conforme mostrado no quadro 1. Assim, o social năo é algo dado ou algo fácil de ser desvendado, há múltiplas verdades sempre contingentes e precárias (MENDONÇA; RODRIGUES, 2008).

Juntamente com a categoria de articulaçáo, Laclau e Mouffe (1985) trazem as categorias de momento, elementos e pontos nodais para corroborar sua concepção de identidade. Momentos são diferentes posicionamentos que aparecem articulados dentro do discurso, enquanto elementos sáo aquelas diferenças que não estáo discursivamente articuladas devido ao caráter flutuante adquirido em períodos de crise social e deslocamentos.

É decisivo o entendimento de que esses elementos são diferenças articuladas, o que faz com que os mesmos tenham, ao mesmo tempo, suas demandas particulares ainda presentes, mas que, em relação à articulação que os envolve, estes cancelam suas diferenças neste instante particular e tão somente neste instante. (MENDONÇA; RODRIGUES, 2008, p. 29).

Nesse sentido, é possível que grupos originalmente antagônicos entre si compartilhem a mesma cadeia articulatória, devido ao fato contingente de terem um inimigo comum. Por fim, os pontos nodais são propostos para a estruturaçáo de elementos em um sistema significativo de momentos, dentro de um discurso; são pontos de referência ou significantes privilegiados em um discurso que une um particular sistema de significados ou uma cadeia de significaçáo.

A análise dos discursos em torno da ADPF 54 nos levou a identificar o direito à interrupçáo da gravidez em caso de fetos anencéfalos como ponto nodal, ao redor do qual circulam as posiçóes antagônicas favoráveis e contrárias, percebidas pela análise das retóricas e argumentaçóes de cada uma das vozes:

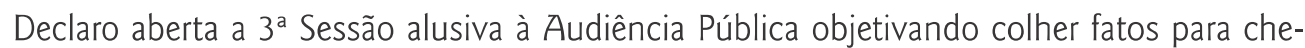
garmos, da forma mais segura possível, à apreciação do tema versado na Arguição de Descumprimento de Preceito Fundamental n 54-8/DF, contando com elementos concretos a revelarem os parâmetros do tema que será objeto de análise pelo Colegiado do Supremo. (Ministro Marco Aurélio, ADPF, 2008c, p. I).

Entende-se que os indivíduos adquirem sua identidade e seu papel na sociedade por estarem posicionados de certa forma por uma série de práti- 
cas inconscientes, rituais, costumes, crenças com os quais se identificam (HOWARTH; NORVAL; STRAVRAKAKIS, 2000; HOWARTH, 2000). Como há uma pluralidade de posiçôes com as quais os indivíduos podem ser identificados, um ator individual pode assumir um número diferente de posiçóes do sujeito. Evidentemente, as vozes ouvidas nas audiências públicas da ADPF 54 refletiram as posiçóes dos sujeitos em defesa dos interesses das instituiçóes que estes representaram.

As pretensões de desqualificação da pessoa humana ferem a dignidade intrínseca e inviolável da pessoa. Só pelo fato de pertencer à espécie humana, esse indivíduo tem uma dignidade; e é essa dignidade que queremos reafirmar, que precisa ser tutelada, que precisa ser respeitada. (Representante do segmento religioso, ADPF, 2008a, p. 6).

O impacto psíquico é muito grande para as mulheres, é devastador. Elas são acometidas por choro, tristeza profunda, frustração, culpa, indignação, sofrimento, pensamentos de morte e acham que elas são as responsáveis por estar acontecendo aquela coisa com o seu bebê, (Representante da Federação Brasileira das Associações de Ginecologia e Obstetrícia, ADPF, 2008b, p. 16).

Fundamental para a TD, o antagonismo é um conceito que explica o processo pelo qual o social torna-se homogeneizado em uma cadeia de equivalências "vis-à-vis" com um exterior puramente negativo (MARCHART, 2008). As pessoas estão juntas naquele discurso, pois ele consegue articular um conjunto de diferenças que de outra forma não estariam reunidas; é um discurso contingente, pois foi esse e não outro capaz de fazer essa articulação.

Assim, os sujeitos que defendem a interrupçáo da gravidez do feto com anencefalia argumentam sobre a laicidade do Estado e o direito da mulher de realizar tal opçáo; de outro lado, estáo os que defendem o direito à vida do feto anencéfalo argumentando que não é possível falar de direito da mulher quando há um direito que a ele se sobrepóe: o direito à vida. A lógica da equivalência funciona entáo pela criação de identidades formadas por discursos que concordam entre si, ainda que nenhum deles seja único ou totalmente livre:

A discussão ora estabelecida visa garantir o direito de escolha da mulher grávida sobre a antecipação do parto nestes casos. O Ministério da Saúde defende essa garantia, fundamentado, entre outras razões, na dolorosa experiência de manejo de situações em que mães são obrigadas a levar sua gestação a termo mesmo sabendo que o feto não sobreviverá após o parto. (Representante do Ministério da Saúde, ADPF, 2008c, p. 4). 
Trata-se, assim, de defender um direito à escolha da mulher que, se desejar levar a termo a gravidez nessa circunstância, está amparada pela lei e pelos serviços de saúde. Entretanto, a não permissão legal para a interrupção da gravidez quando a gestante assim o deseja é um grave desrespeito a seus direitos. Prevalece um concepto sem qualquer possibilidade de vida sobre uma cidadã plenamente capaz de tomar decisões e arcar com as suas consequências. Essa mulher é cidadã de um país democrático, plural e regido por um estado laico. A separação entre igreja e estado é um pilar da nossa República e a sua defesa é fundamental para os direitos civis, políticos, sexuais e reprodutivos de todos os brasileiros e brasileiras. (Representante do Conselho Nacional dos Direitos da Mulher, ADPF, 2008c, p. 96).

Por outro lado, a lógica da diferença faz exatamente o contrário: "consiste na expansão de um dado sistema de diferenças pela dissoluçáo de cadeias existentes de equivalência e incorporação de elementos desarticulados em uma ordem em expansão" (HOWARTH; NORVAL; STRAVRAKAKIS, 2000, p. 11).

Em outras palavras, se mudarmos o foco ou tema do debate, é possível que os sujeitos rearticulem-se em outras cadeias de equivalência por meio de deslocamentos. Por exemplo, embora a visão médico-científica seja predominantemente favorável ao direito da mulher em casos de anencefalia, há posiçôes contrárias, como as esboçadas pela Comissáo de Ética e Cidadania da Academia Fluminense de Medicina, segundo a qual

A violência contra um ser humano indefeso não é compatível com a consciência ética do médico nem com a missão e a nobreza da medicina. O aborto terapêutico é questionado por várias autoridades médicas. (ADPF, 2008c, p. 84).

É preciso que se instalem - e eu me proporia, na minha área, a auxiliar - grupos de acolhida que não levem ao caixão, que não levem ao abortamento, que não levem à antecipação do parto, porque acredito que vivemos em um mundo de construção. Senhor Ministro, na qualidade de médica e de professora de medicina, é muito difícil falar em desconstruir. Pediria que lembrássemos de viver em um mundo em que ainda reste esperança, sem desconstruir e sem eugenia. (Representante da Associação de Desenvolvimento da Família. (ADPF, 2008c, p. 34).

Para esses sujeitos, a vida humana deve ser preservada e defendida por todos, principalmente pelo poder público. Sobre essa tutela do Estado, as vozes ouvidas nas audiências públicas analisadas náo apresentaram divergências; o questionamento está em torno de quando é possível diagnosticar a morte, ou seja, é possível afirmar que um feto com batimentos cardíacos e diagnóstico seguro de morte cerebral tenha vida? 
Além disso, a Comissão de Ética e Cidadania e outros representantes do segmento social rejeitaram a possibilidade de diagnóstico de anencefalia quando o bebê está no ventre materno, indicando que a possibilidade da interrupçáo terapêutica pode ser danosa à máe e fazendo links da anencefalia com o eugenismo e o aborto intencional (ADPF, 2008d). Dessa forma, uma nova cadeia de diferença está formada. Cabe lembrar que essa contingência da estrutura discursiva só é possível em virtude da categoria deslocamento, a qual acentua o caráter contingencial da arena social e política. Isso acontece porque o deslocamento cria um espaço no nível do significado que estimula novas construçóes discursivas, as quais aparecem para corrigir a estrutura deslocada.

Por tais motivos, é possível afirmar que a fixação de sentidos em um discurso é sempre parcial, precária e contingente, ou seja, não se pode garantir que determinado discurso a priori consiga articular outros discursos. Assim sendo, a hegemonia discursiva para Laclau é entendida como um lugar vazio e, como tal, foco de incessantes disputas entre os múltiplos discursos dispersos no campo da discursividade (MENDONÇA, 2009).

O conceito de hegemonia é central para a TD. "Práticas hegemônicas sáo uma forma exemplar de atividade política que envolve articulaçáo de identidades diferentes e subjetividades em um projeto comum, enquanto formação hegemônica é o resultado desses projetos" (MENDONÇA, 2009, p. 14). Podemos afirmar que as condiçóes sine qua non para as práticas hegemônicas são a existência de forças antagonistas e a instabilidade das fronteiras políticas que as dividem. "Um discurso hegemônico é essencialmente um discurso sistematizador, aglutinador. É, enfim, um discurso de unidade: unidade de diferenças." (MENDONÇA, 2009, p. 158).

Os debates e as tensóes que se deram nas audiências do STF mostraram uma disputa de posiçóes por uma significação hegemônica, no caso da ADPF 54 , a questáo da interrupçáo da gravidez nos casos de anencefalia. Alguns sujeitos definiram-na como uma defesa da laicidade do Estado, bem como do direito da mulher sobre seu corpo e sua psiquê, enquanto outros defenderam outras causas - o direito à vida. Com a decisáo do STF pelo direito da mulher de interromper a gravidez no caso de fetos anencéfalos em abril de 2012, uma demanda particular assumiu a representaçáo de um conjunto de outras demandas igualmente particulares, passando a falar em nome de tal conjunto (BURITY, 2008). 


\section{Comentários últimos}

A interrupçáo da gravidez sempre foi um tema polêmico a ser tratado por uma sociedade, e no Brasil náo é diferente. O julgamento pelo STF da Arguiçáo de Descumprimento de Preceito Fundamental no 54 representou um marco na história do país, quando se tomou a decisão por regulamentar o direito da máe a decidir pela permanência ou náo da gravidez em casos de anencéfalos, o que aconteceu depois de um amplo debate promovido pelas audiências públicas realizadas pelo STF, cujos discursos foram alvo de apreciaçáo neste trabalho.

A legalizaçáo da interrupçáo se coaduna com as permissóes presentes no Art. 128 do Código Penal brasileiro, de 1940, para prever as situaçóes que tornam possíveis as práticas de aborto. A decisáo do STF possibilitou o exercício do direito da mãe a interromper sua gravidez, mas condicionou alguns procedimentos indispensáveis para tal exercício, entre os quais estáo o necessário esclarecimento médico à gestante e o diagnóstico preciso realizado por pelo menos dois profissionais. Questionamos, entretanto, a garantia de tal direito pelo SUS, especialmente nas áreas mais afastadas dos grandes centros, muito embora tenha havido garantia de possibilidade pelo Ministro da Saúde (ADPF, 2008c).

Por meio da TD de Lalau e Mouffe, foi possível identificar os agentes que se articularam e a forma como se organizaram em torno de um ponto nodal: o direito à interrupçáo da gravidez em caso de fetos anencéfalos. Religiáo, Estado, sociedade e comunidade científica apresentaram elementos de persuasáo em torno da causa, os quais apontaram para dois caminhos antagônicos, o favorável e o contrário à prática da interrupçáo da gravidez. Por trás desse debate, encontram-se diversas convicçóes, que trazem consigo princípios que tentam balizar uma forma de viver, mas que náo conseguem ser unânimes no que se busca, gerando, assim, os conflitos.

Como consequência, cadeias de equivalência foram formadas por atores que eventualmente poderiam estar em posiçóes antagônicas, mas que, no debate sobre a ADPF 54, aproximaram-se contingencialmente. Assim, os atores que estáo juntos em um discurso - seja ele contra, seja a favor da interrupçáo terapêutica - na verdade assumem posiçóes para conseguir articular um conjunto de diferenças que de outra forma náo estariam reunidas.

Assim, a contribuiçáo da TD vai na direçáo de questionar os limites de uma ingênua realidade que ignora ou negligencia as dimensóes políticas e 
culturais constitutivas do mundo social (SOUZA; CORREA; MELO, 2009). Percebemos que os debates em torno da ADPF 54 foram além de argumentos científicos e religiosos na medida em que refletiram as lógicas discursivas, os posicionamentos políticos e as ideologias de grupos sociais envolvidos.

\section{Referências}

ADPF. AUDIÊNCIA PÚBLICA DA ARGUIÇÃO DE DESCUMPRIMENTO DE PRECEITO FUNDAMENTAL No 54. Portal do STF, 2008a. Disponível em: <http://www.stf.jus.br/arquivo/cms/ processoAudienciaPublicaAdpf54/anexo/ADPF54_notas_dia_26808.pdf>. Acesso em: 10 jul. 2012.

AUDIÊNCIA PÚBLICA DA ARGUIÇĀO DE DESCUMPRIMENTO DE PRECEITO FUNDAMENTAL No 54. Portal do STF, 2008b. Disponível em: <http://www.stf. jus.br/arquivo/cms/processoAudienciaPublicaAdpf54/anexo/ADPF54_notas_dia_28808.pdf>. Acesso em: 10 jul. 2012.

AUDIÊNCIA PÚBLICA DA ARGUIÇĀO DE DESCUMPRIMENTO DE PRECEITO FUNDAMENTAL No 54. Portal do STF, 2008c. Disponível em: <http://www.stf. jus.br/arquivo/cms/processoAudienciaPublicaAdpf54/anexo/ADPF54_notas_dia_4908.pdf>. Acesso em: 10 jul. 2012.

AUDIÊNCIA PÚBLICA DA ARGUIÇÃO DE DESCUMPRIMENTO DE PRECEITO FUNDAMENTAL No 54. Portal do STF, 2008d. Disponível em: <http://www.stf. jus.br/arquivo/cms/processoAudienciaPublicaAdpf54/anexo/ADPF54_notas_dia_16908.pdf>. Acesso em: 10 jul. 2012.

ANIS. INSTITUTO DE BIOÉTICA, DIREITOS HUMANOS E GÊNERO. Anencefalia: pensamento brasileiro em sua pluralidade. Brasília: Letras Livres, 2004. Disponível em: <http:// www.anis.org.br/Arquivos/Textos/pluralidade_final.pdf>. Acesso em: 5 jul. 2012.

BAUER, M. W.; AARTS, B. A construçáo do corpus: um princípio para a coleta de dados qualitativos. In: BAUER, M. W.; GASKELL, G. Pesquisa qualitativa com texto, imagem e som: um manual prático. Petrópolis, RJ: Vozes, 2002. p. 39-63.

BURITY, J. Discurso, política e sujeito na teoria da hegemonia de Ernesto Laclau. In: MENDONÇA, D.; RODRIGUES, L. P. (Org.). Pós-estruturalismo e teoria do discurso em torno de Ernesto Laclau. Porto Alegre: EdiPUCRS, 2008. p. 35-51.

CARVALHO, F. T. F. T.; YOUNG, C. F. T. de C. Aborto de feto anencefálico. Âmbito Jurídico, Rio Grande, ano XV, n. 100, maio 2012. Disponível em: <http://www.ambito-juridico.com.br/ site/index.php?n_link=revista_artigos_leitura\&artigo_id=11610>. Acesso em: 15 jul. 2012. 
CFM. CONSELHO FEDERAL DE MEDICINA. Resoluçáo n. 1.752, de 8 de setembro de 2004. Autorizaçáo ética do uso de órgáos e/ou tecidos de anencéfalos para transplante, mediante autorização prévia dos pais. Brasília: Conselho Federal de Medicina, 2004.

DINIZ, D.; DAMASCENO, A. P. Mulheres, mídia e aborto. Série Anis 20, p. 1-8, 2001. Disponível em: <http://www.anis.org.br/serie/artigos/sa20(dinizdamasceno)midiaaborto.pdf>. Acesso em: 15 jul. 2012.

; VÉLEZ, A. C. G. Aborto na Suprema Corte: o caso da anencefalia no Brasil. Revista Estudos Feministas. Florianópolis, v. 16, n. 2, p. 647-652, maio-agosto 2008. . et al. A magnitude do aborto por anencefalia: um estudo com médicos. Ciência \& Saúde Coletiva, 14, p. 1.619-1.624, 2009. (Supl., 1).

DOMINGUES, R. C. Entre normas e fatos, o direto de decidir: o debate sobre o aborto à luz dos princípios constitucionais. In: MAIA, M. B. (Org.). Direito de decidir: múltiplos olhares sobre o aborto. Belo Horizonte: Autêntica, 2008. p. 67-104.

FRANCO, S. Aborto de anencéfalos: o dia seguinte da decisão do STF. 2012. Disponível em: $<$ http://www.migalhas.com.br/dePeso/16,MI153900,21048-Aborto+de+anencefalos+o+dia+segui nte+da+decisao+do+STF. Acesso em: 15 jul. 2012.

HOWARTH, D. Discourse. United Kingdom: Open University Press, 2000.

; STAVRAKAKIS, Y. Introducing discourse theory and political analysis. In: HOWARTH, D.; NORVAL, A. J.; STRAVRAKAKIS, Y. Discourse theory and political analysis. Manchester: Manchester University Press, 2000. p. 1-23.

; NORVAL, A.; STAVRAKAKIS, Y. Discourse theory and political analysis. Manchester: Machester University Press, 2000.

KIRIMI, M. C.; PINNA, R. Aborto de anencéfalo: colisāo entre legalidade x moralidade. Revista de Ciências Jurídicas e Sociais, v.1, n.1, 2011. Disponível em: <http://revistas.ung.br/index.php/ cienciasjuridicasesociais/article/viewFile/906/884>. Acesso em: 15 jul. 2012.

LACLAU, E. On populist reason. London: Verso, 2005.

; MOUFFE, C. Hegemony and socialist strategy. London: Verso, 1985.

MARCHART, O. Teoria do discurso, pós-estruturalismo e paradigma da Escola de Essex. In: MENDONÇA, D.; RODRIGUES, L. P. (Org.). Pós-estruturalismo e teoria do discurso em torno de Ernesto Laclau. Porto Alegre: EdiPUCRS, 2008. p. 10-14. 
MELLO, F. F. O processo de descriminalizaçáo do aborto de anencéfalo no Brasil. 2012. Disponível em: <http://drauziovarella.com.br/saude-da-mulher/o-processo-de-descriminalizacaodo-aborto-de-anencefalo-no-brasil/>. Acesso em: 14 jul. 2012.

MENDONÇA, D.; RODRIGUES, L. P. Em torno de Ernesto Laclau. In: (Org.).

Pós-estruturalismo e teoria do discurso: em torno de Ernesto Laclau. Porto Alegre, 2008. p. 25-33.

NINDS. NATIONAL INSTITUTE OF NEUROLOGICAL DISORDERS AND STROKE.

Ninds anencephaly information page. Bethesda, MD: Ninds, 2007. Disponível em: <http:// www.ninds.nih.gov/disorders/anencephaly/anencephaly.htm>. Acesso em: 15 jul. 2012.

REDE FEMINISTA DE SAÚDE. Dossiê aborto: mortes preveníveis e evitáveis. Belo Horizonte: Rede Feminista de Saúde, 2005.

RIBEIRO; F. R. G.; SPINK, M. J. P. Estratégias retóricas na controvérsia moral sobre a legalizaçáo do aborto: o caso da anencefalia no Brasil. Interface - Comunicaçáo, Saúde, Educaçáo, v. 16, n. 40 , p. 35-49, jan./mar. 2012.

SOUZA, A. C. R.; CORREA, M. I. S.; MELLO, S. C. B. de. Os desafios da constituiçáo de uma rede organizacional no setor de vitivinicultura do Vale do Sáo Francisco. In: IFBAE - CONGRÈS DE I INSTITUT FRANCO-BRÉSILIEN D ADMINISTRATION DES ENTREPRISES, 5., 2009, Grenoble. Anais... Grenoble, 2009. Disponível em: <http://www.ifbae.com.br/congresso5/ pdf/B0091.pdf>. Acesso em: 12 ago. 2014.

Recebido em: 07/03/2013

Aprovado em: 20/03/2014

\section{The right to termination of pregnancy of anencephalic fetus: voices and discursive logic present in ADPF 54}

\section{Abstract}

In this paper we sought to analyze the logic of the political debates surrounding the Claim of Breach of Fundamental Precept 54 (ADPF 54), which transferred to the woman's decision by continuity or termination of pregnancy of anencephalic fetus. We used a Discourse Theory of Laclau and Mouffe to identify speeches, joints, nodal points and the groups involved in the debate. Thus, we carefully analyzed the speeches transcribed by shorthand notes available on the website of the Supreme Court dealing with the four public hearings. It was found that religious entities, state, civil society and scientific community had elements of persuasion around the 
cause that showed two antagonistic ways. Equivalence chains were formed by actors who could possibly be in antagonistic positions, but the debate on ADPF54 approached contingently. The debates around 54 ADPF go beyond religious and scientific arguments: the logical discourse reflected the political positions and ideologies of social groups involved.

Keywords: Discourse Theory. Laclau and Mouffe. ADPF 54. Anencephaly. 